OPEN ACCESS

Edited by:

Hung-Ju Yen,

Academia Sinica, Taiwan

Reviewed by:

Huanwen Wang,

China University of Geosciences

Wuhan, China

Maria Graca Rasteiro,

University of Coimbra, Portugal

${ }^{*}$ Correspondence:

Kailong Zhang

klzhang@hyit.edu.cn

Liangbiao Wang

Ibwang@jsut.edu.cn

Tao Mei

meitao@hubu.edu.cn

tThese authors have contributed equally to this work

Specialty section:

This article was submitted to

Physical Chemistry and Chemical

Physics,

a section of the journal

Frontiers in Chemistry

Received: 07 December 2020

Accepted: 27 January 2021

Published: 11 March 2021

Citation:

Liu S, Luo J, Xiong Y, Chen Z, Zhang K, Rui G, Wang L, Hu G, Jiang J and Mei T (2021) Taming Polysulfides in an Li-S Battery With Low-Temperature Onestep Chemical Synthesis of Titanium

Carbide Nanoparticles From Waste PTFE.

Front. Chem. 9:638557.

doi: $10.3389 /$ fchem.2021.638557

\section{Taming Polysulfides in an Li-S Battery With Low-Temperature One-step Chemical Synthesis of Titanium Carbide Nanoparticles From Waste PTFE}

\author{
Suyao Liu $^{1 \dagger}$, Jun Luo ${ }^{1 \dagger}$, Yuting Xiong ${ }^{2}$, Zhe Chen ${ }^{3}$, Kailong Zhang ${ }^{1 *}$, Guofeng Rui ${ }^{1}$, \\ Liangbiao Wang $^{3 *}$, Guang $\mathrm{Hu}^{1}$, Jinlong Jiang ${ }^{1}$ and $\mathrm{Tao}^{\mathrm{Mei}}{ }^{2 *}$
}

${ }^{1}$ Key Laboratory for Palygorskite Science and Applied Technology of Jiangsu, National \& Local Joint Engineering Research Center for Mineral Salt Deep Utilization, School of Chemical Engineering, Huaiyin Institute of Technology, Huaian, China, ${ }^{2}$ Hubei Collaborative Innovation Center for Advanced Organic Chemical Materials, Ministry-of-Education Key Laboratory for the Green Preparation and Application of Functional Materials, Hubei Key Laboratory of Polymer Materials, School of Materials Science and Engineering, Hubei University, Wuhan, China, ${ }^{3}$ School of Chemistry and Environment Engineering, Jiangsu University of Technology, Changzhou, China

In this work, titanium carbide $(\mathrm{TiC})$ nanoparticles have been successfully synthesized at much lower temperatures of $500^{\circ} \mathrm{C}$ using cheaper starting materials, such as waste polytetrafluoroethylene (PTFE) (carbon source) and titanium and metallic sodium, than the traditional carbothermal reduction of $\mathrm{TiO}_{2}$ at $1,800^{\circ} \mathrm{C}$. An XRD pattern proved the formation of face-centered cubic TiC, and TEM images showed the obtained TiC nanoparticles with an average size of approximately $50 \mathrm{~nm}$. In addition, the separator coated with TiC nanoparticles as an active material of interlayer effectively mitigates the shuttling problem by taming the polysulfides in Li-S batteries compared with a traditional celgard separator. The assembled cell realizes good cycling stability with $501 \mathrm{mAh}^{-1}$ and a low capacity fading of $0.1 \%$ per cycle after 300 cycles at $1 \mathrm{C}$ due to high utilization of the sulfur-based active species.

Keywords: chemical synthesis, titanium carbide, X-ray diffraction pattern, nanoparticles, Li-S batteries

\section{INTRODUCTION}

Transition metal carbides have recently received much attention for their important applications in the mechanical and aerospace industries (Das et al., 2002; Rasaki et al., 2018). Among transition metal carbides, titanium carbide (TiC) is an important non-oxide ceramic material due to its good chemical stability, extreme hardness, high melting point (about $3,200^{\circ} \mathrm{C}$ ), high Young's modulus, low density $(4.93 \mathrm{~g} / \mathrm{ml}$ ), and good electrical and thermal conductivity (Wang et al., 2012a; Wang et al., 2012b; Xiao et al., 2016). Recently, TiC has been considered for use in energy storage due to its outstanding characteristics (Liu et al., 2018; Cui et al., 2019; Cai et al., 2020; Geng et al., 2021). Specifically, in an Li-S battery, the synthesized $\mathrm{TiC}$ can be used to enhance the cycling performance through the strong polar binding interactions with sulfur species and can better suppress the diffusion of lithium polysulfides (LiPS) compared with other materials (Zhang et al., 2016; Cui et al., 2018; Zhang et al., 2018; Zhang et al., 2019). The strong chemical sorption and high electrical conductivity make it an ideal sulfur host for Li-S batteries. Mei and co-workers successfully prepared 
a $\mathrm{TiC}-\mathrm{TiO}_{2} / \mathrm{S}$ composite and the result shows that the cathode with a $\mathrm{TiC}-\mathrm{TiO}_{2} / \mathrm{S}$ composite delivers a high initial discharge specific capacity of $1,218 \mathrm{mAh} \mathrm{g}^{-1}$ at $1 \mathrm{C}$ rate (Cui et al., 2019). In the $\mathrm{TiC}-\mathrm{TiO}_{2} / \mathrm{S}$ composite, $\mathrm{TiC}$ can not only chemically bond with polysulfides but also improve the electrical conductivity of the assembled cells (Cui et al., 2019; Geng et al., 2021). The result also shows that it can promote the conversion kinetics of LiPS to final $\mathrm{Li}_{2} \mathrm{~S}_{2} / \mathrm{Li}_{2} \mathrm{~S}$ during the electrochemistry of $\mathrm{Li}-\mathrm{S}$ batteries (Zhang et al., 2020). Based on this, Zhang designed and synthesized multi-yolk/shell structured TiC@C nanofibers as a strong sulfur host. Owing to its chemisorption, active electrocatalysis, and high electrical conductivity properties, the as-prepared sulfur-based cathode shows an unforgettable areal capacity of $6.81 \mathrm{~mA} \mathrm{~h} \mathrm{~cm}^{-2}$ over 800 cycles with a high sulfur loading $(10.5 \mathrm{mg})$. Therefore, $\mathrm{TiC}$ nanoparticles are a popular candidate for inhibiting the LiPS shutting effect (the main problem in Li-S batteries) (Cai et al., 2020).

Traditionally, the industrial method of producing $\mathrm{TiC}$ is the carbothermal reduction of $\mathrm{TiO}_{2}$ at high temperatures (Berger et al., 1999; Cai et al., 2020). Over the past decades, various other methods have been reported to synthesize TiC, including selfpropagating high-temperatures synthesis (SHS) (Song et al., 2009), mechanochemical synthesis (Lyakhov et al., 2018), sonochemical (Sivasankaran and Kumar, 2015), meltingcasting (Liu et al., 2014), improved carbothermal reduction (Yu et al., 2020), metallic thermal reduction (Lee et al., 2004), spark plasma sintering technique (Saba et al., 2018), chemical vapor deposition (Qi et al., 2000; Wokulski and Wolaska, 1983), mechanical alloying (MA) (Razavi et al., 2007), and so on (Wang et al., 2016; Fei et al., 2020). As everyone knows, waste plastic is solid waste with a high carbon content. Therefore, the waste plastic can be used as raw materials to synthesize high-valued carbon-based materials and carbides (Wang et al., 2017; Wang et al., 2018; Dai et al., 2019; Wang et al., 2019a; Wang et al., 2019b; Wang et al., 2019c; Wang et al., 2019d). In this study, we have developed a new method to synthesize $\mathrm{TiC}$ nanoparticles by using waste PTFE as a carbon source at a low temperature of $500^{\circ} \mathrm{C}$. The formation mechanism of $\mathrm{TiC}$ has been discussed preliminarily. And its taming of LiPS by coating TiC nanoparticles on one side of the separator in an Li-S battery has been investigated. The result proves that the assembled cell achieved a higher specific capacity at the same rate and lower capacity loss in long-cycle performances compared with a traditional celgard separator.

\section{EXPERIMENT}

\section{Synthesis of TiC Nanoparticles}

The titanium powder, metallic sodium, sulfur powder, N-methyl2-pyrrolidone (NMP), and $\mathrm{Li}_{2} \mathrm{~S}$ powder used in experiments were purchased from Sinopharm Chemical Reagent Co., Ltd. Super P and polyvinylidene fluoride (PVDF, HSV900) were bought from Lizhiyuan Store (Taiyuan city, Shanxi Province, China). All chemicals were used directly without further treatment. Metallic titanium $(0.40 \mathrm{~g})$, waste PTFE (obtained from waste teflon-lined, $0.50 \mathrm{~g})$, and excess metallic sodium $(1.00 \mathrm{~g})$ were put into a stainless autoclave of $22 \mathrm{ml}$ capacity. After sealing, the stainless autoclave was kept at $500^{\circ} \mathrm{C}$ for $10 \mathrm{~h}$ and then cooled to $30^{\circ} \mathrm{C}$. The product was collected from the autoclave and washed with absolute ethanol and diluted with $\mathrm{HCl}$ several times to remove the byproducts and unreacted sodium. The obtained black powder was dried at $70^{\circ} \mathrm{C}$ for several hours under vacuum.

\section{Preparation of Sulfur Electrode}

Melt-diffusion method was conducted to prepare the Super P/S $(\mathrm{C} / \mathrm{S})$ composite. A mixture of Super $\mathrm{P}$ and $\mathrm{S}$ (with a weight ratio of 4:6) was grounded in an agate mortar for $20 \mathrm{~min}$. Then, the collected powder was transferred into a quartz tube and heated at $155^{\circ} \mathrm{C}$ for another $24 \mathrm{~h}$ to obtain a C/S composite. Subsequently, the $\mathrm{C} / \mathrm{S}$ composite and PVDF were mixed (with a weight ratio of 9:1) to form homogeneous slurry with drops of NMP. The slurry was coated onto one side of the aluminum foil, and the coated aluminum foil was dried in a vacuum oven at $70^{\circ} \mathrm{C}$ for $12 \mathrm{~h}$. Lastly, the dried coated aluminum foil was punched into discs (with a diameter of $12 \mathrm{~mm}$ ). The sulfur loading is about $1.6-2.0 \mathrm{mg} \mathrm{cm}^{-2}$.

\section{Preparation of Modified Separator}

The obtained TiC (80 mg), Super P (10 mg), and PVDF (10 mg) binder were grinded for $10 \mathrm{~min}$ before being dispersed in NMP. After adding NMP, further sequential grinding for 10-15 min was taken to form homogeneous slurry. Then the slurry was coated on one side of a (celgard 2500) separator. The modified separator was dried at $40^{\circ} \mathrm{C}$ under vacuum for $10 \mathrm{~h}$. Finally, the modified separator was cut into a circle with a diameter of $19 \mathrm{~mm}$.

\section{Adsorption Study of TiC}

$\mathrm{Li}_{2} \mathrm{~S}_{6}$ solution was prepared by mixing sulfur powder and $\mathrm{Li}_{2} \mathrm{~S}$ with a molar ratio of 5:1 in tetrahydrofuran (THF) solvent, followed by stirring at $40^{\circ} \mathrm{C}$ for $24 \mathrm{~h}$ in a confined glass bottle in an Ar-filled glove box. Twenty milligram of $\mathrm{TiC}$ powder was dispersed in $10 \mathrm{ml} \mathrm{Li}_{2} \mathrm{~S}_{6} / \mathrm{THF}$ solution with a concentration of $5 \mathrm{mmol} \mathrm{L}{ }^{-1}$. The mixtures were kept standing for $2 \mathrm{~h}$ to observe the color change.

\section{Characterization}

The final product $(\mathrm{TiC})$ was characterized by X-ray powder diffraction (XRD, Philips X'Pert diffractometer with $\mathrm{Cu}-\mathrm{Ka}$ radiation $\lambda=1.54178 \AA$ ) and field-emission scanning electron microscopy (JEOL-JSM-6700F). High Resolution-Transmission electron microscopy (HR-TEM) images and selected area electron diffraction (SAED) of $\mathrm{TiC}$ nanoparticles were performed on a JEOL-2010 transmission electron microscope. The photos of LiPS adsorption experiment and separator coated with TiC nanoparticles were taken by iPhone 7 .

\section{Electrochemical Measurements}

Electrochemical measurements were carried out with coin-type 2032 half cells in an Ar-filled glove box $\left(\mathrm{H}_{2} \mathrm{O}<0.1\right.$ ppm, $\mathrm{O}_{2}<$ $0.1 \mathrm{ppm})$. The $\mathrm{Li}-\mathrm{S}$ cell was assembled with $\mathrm{C} / \mathrm{S}$ cathode, one piece of separator, and lithium metal with $1 \mathrm{~mol} \mathrm{~L}^{-1}$ bis (trifluoromethane) sulfonimide lithium salt (LiTFSI) dissolved in a mixture of 1,2-dimethoxyethane (DME) and 1,3-dioxolane (DOL) $(\mathrm{v} / \mathrm{v}=1 / 1)$ containing $\mathrm{LiNO}_{3}(2 \mathrm{wt} \%)$. The cells were 

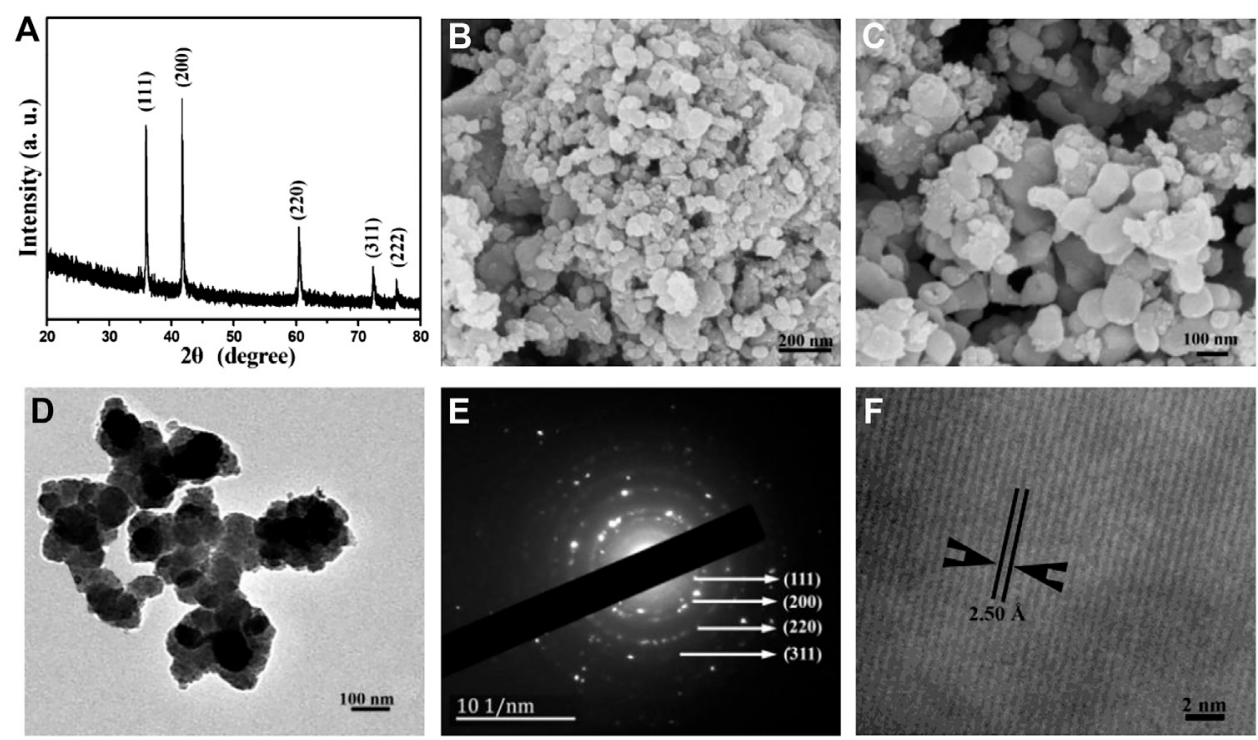

FIGURE1 | (A) XRD pattern, (B) Low-magnification SEM image, (C) High-magnification SEM image, (D) TEM image, (E) SAED pattern, and (F) HR-TEM image of the as-obtained TiC nanoparticles.

cycled in the voltage range of $1.7-2.8 \mathrm{~V}$. The electrochemistry impedance spectroscopy (EIS) was tested on a CHI660e electrochemical workstation $(100 \mathrm{kHz}-0.01 \mathrm{~Hz})$ using an open circuit voltage. The cycling performance and rate performance were based on the galvanostatic test $\left(1 \mathrm{C}=1,675 \mathrm{~mA} \mathrm{~g}^{-1}\right)$.

\section{RESULTS AND DISCUSSION}

The XRD pattern of the as-obtained product TiC (shown in Figure 1A) was used to investigate the crystal structures. All the diffraction peaks with strong diffraction intensity centered at $2 \theta=$ $35.91^{\circ}, 41.73^{\circ}, 60.45^{\circ}, 72.37^{\circ}$, and $76.16^{\circ}$, which can be indexed as the (111), (200), (220), (311), and (222) diffraction planes of the face-centered cubic titanium carbide, respectively. The refined lattice parameter $a=4.3253 \AA$ is extracted from the XRD pattern, which is close to the literature value of $a=4.3270 \AA$ (JCPDS card No. 65-0242). No other diffraction peaks in the XRD pattern from impurity have been found. The XRD pattern proves the wellcrystallized face-centered cubic structure of $\mathrm{TiC}$ powder. $\mathrm{TiC}$ has been obtained from the reaction of metallic titanium, waste PTFE, and metallic sodium under the present synthetic conditions.

SEM is used to investigate the morphology and size of the product. A representative SEM image of the obtained TiC product is shown in Figure 1B, which apparently shows that the product is mainly composed of nanoparticles with a diameter of $30-100 \mathrm{~nm}$. From a high magnification SEM image (Figure 1C), it can be clearly observed that TiC nanoparticles aggregate into chainlike nanostructures.

A typical TEM image of the TiC sample is shown in Figure 1D. The size of the obtained TiC nanoparticles shows an average of $\sim 50 \mathrm{~nm}$. Furthermore, the highly crystalline nature of the product was confirmed by the SAED pattern shown in
Figure 1E. The diffraction rings can be indexed as (111), (200), (220), (311), and (222) reflections according to the cubic structure of polycrystalline $\mathrm{TiC}$, which is consistent with the $\mathrm{XRD}$ result. HR-TEM is used to further investigate the detailed structure of nanocrystalline TiC. As shown in Figure 1F, the lattice spacing is measured to be $2.50 \AA$, which corresponds to the (111) plane in cubic phase TiC.

In our experiment, the approach to synthesize $\mathrm{TiC}$ nanoparticles is based on a chemical reaction with metallic sodium, waste PTFE, and metallic titanium. The chemical reaction can be expressed as follows:

$$
2 \mathrm{Na}+\mathrm{Ti}+1 / \mathrm{n}\left[\mathrm{CF}_{2}\right]_{\mathrm{n}} \rightarrow 2 \mathrm{NaF}+\mathrm{TiC}
$$

During the reaction process, waste PTFE broke down by metallic sodium to produce carbon with the increasing reaction temperature (Eq. 2). Then, TiC nanoparticles can be prepared from the following chemical reaction with carbon atoms and metallic titanium due to the high reactivity of the newly formed carbon atoms (Eq. 3). The chemical reactions in the autoclave may be expressed as follows:

$$
\begin{gathered}
2 \mathrm{Na}+1 / \mathrm{n}\left[\mathrm{CF}_{2}\right]_{\mathrm{n}} \rightarrow 2 \mathrm{NaF}+\mathrm{C} \\
\mathrm{Ti}+\mathrm{C} \rightarrow \mathrm{TiC}
\end{gathered}
$$

As the standard molar enthalpies formation of $\mathrm{NaF}$ is negative $\left(\Delta_{\mathrm{r}} H_{\mathrm{m}, \mathrm{NaF}}=-572.63 \mathrm{~kJ} \mathrm{~mol}^{-1}\right)$, a very large amount of heat has been generated in the reaction Eq. 2, promoting the formation of $\mathrm{TiC}$ nanoparticles at a low reaction temperature of $500^{\circ} \mathrm{C}$.

To further study the interactions between $\mathrm{TiC}$ and LiPS, the visual effect is given by dispersed $\mathrm{TiC}$ nanoparticles in $5 \mathrm{mmol} \mathrm{L}^{-1}$ LiPS solution. As shown in Figures $2 \mathrm{~A}, \mathbf{B}$, the color of the bottle labeled with $\mathrm{TiC}-\mathrm{Li}_{2} \mathrm{~S}_{6}$ changes from dark yellow to almost transparent after adsorption for $2 \mathrm{~h}$, while the 

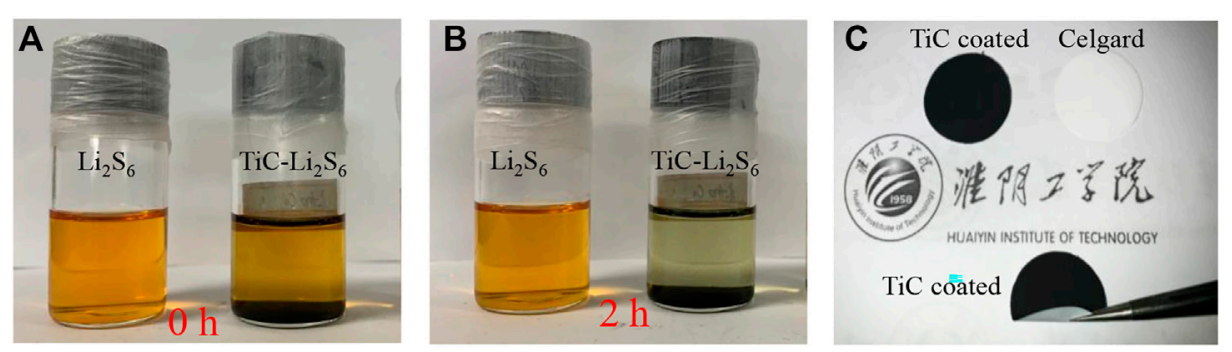

FIGURE 2 | The optical images of the LiPS adsorption experiment: (A) Before and (B) After rest for $2 \mathrm{~h}$, (C) Photographs of the of the separator coated with TiC nanoparticles and bend test.
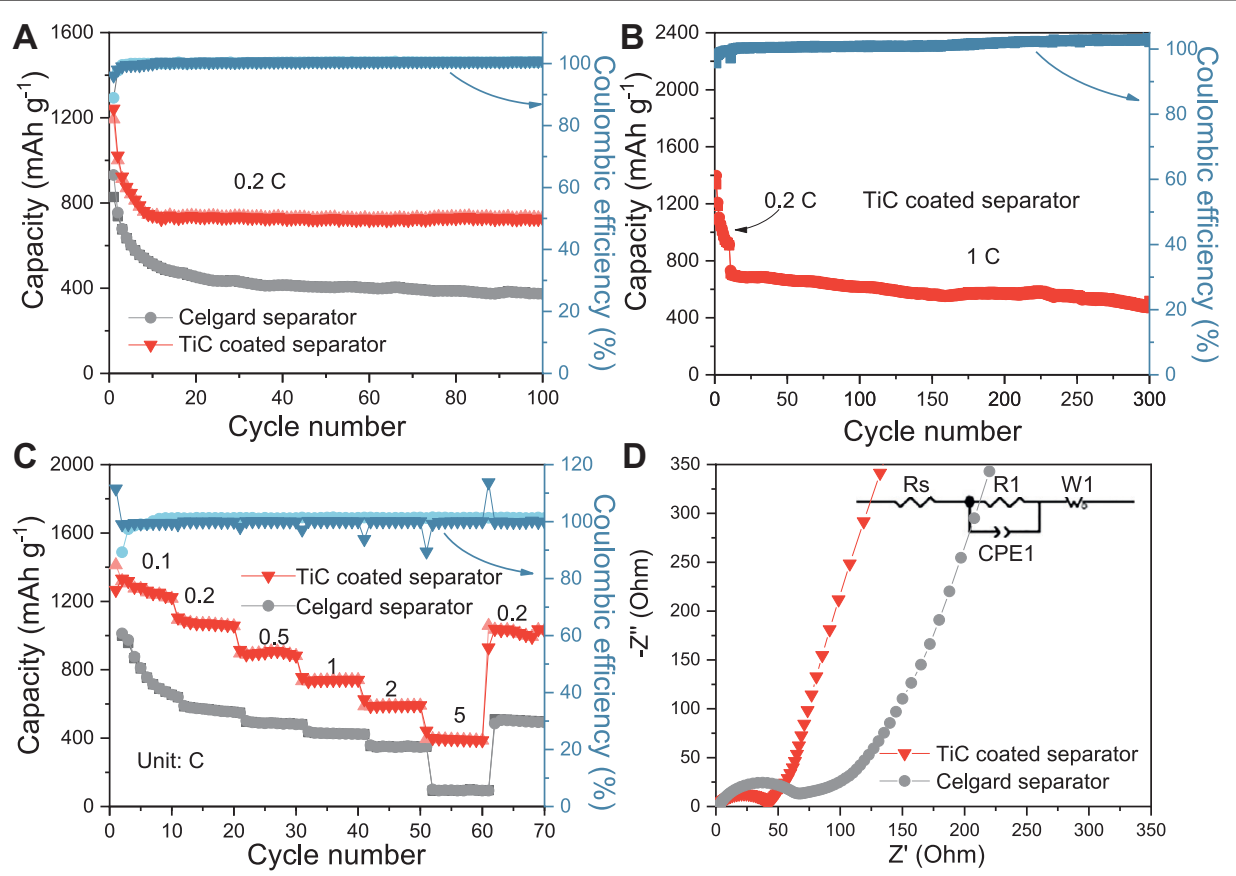

FIGURE 3 | (A) Cycling performance at $0.2 \mathrm{C}$, (B) Long term cycling performance at $1 \mathrm{C}$ based on $\mathrm{C} / \mathrm{S}$ cathode and TiC coated separator, (C) Multi-rate performance of the cells based on $\mathrm{C} / \mathrm{S}$ cathode with celgard and TiC-coated separators, (D) EIS of the cells based on C/S cathode with celgard and TiC-coated separators before cycle.

bottle labeled with $\mathrm{Li}_{2} \mathrm{~S}_{6}$ remains unchanged. This result indicates that as-prepared $\mathrm{TiC}$ nanoparticles have great potential in inhibiting LiPS shuttling in Li-S batteries (Zhang et al., 2020). Considering the merit of the coating separator, TiC nanoparticles were coated on one side of a celgard 2500 separator with Super P and PVDF serving as a functional separator for coin cells. The photos of both the separator coated with $\mathrm{TiC}$ nanoparticles and the common celgard separator are shown in Figure 2C. The reversible bend test also gives strong proof of an excellent adhesion of $\mathrm{TiC}$ to the separator without any powder. Therefore, the dissolved LiPS cannot easily shuttle through the separator (Xu et al., 2019). This also provides a great potential in keeping the intact structure for a long performance period.

Using $\mathrm{TiC}$ nanoparticles to construct a separator modifier, cycling performances and rate performances were systemically studied. As exhibited in Figure 3A, the battery using the same cathode but with a TiC-nanoparticles-coated-separator delivers a high initial specific capacity of $1,242 \mathrm{mAh} \mathrm{g}^{-1}$, and the specific capacity can remain at $736 \mathrm{mAh} \mathrm{g}^{-1}$ after 100 cycles at $0.2 \mathrm{C}$ rate, which are higher than those of the battery composed of a C/S cathode with a celgard separator (827 and $373 \mathrm{mAh} \mathrm{g}^{-1}$ ). Moreover, the long-term cycling performance was also researched (Figure 3B). The battery-based TiC coated separator shows specific capacity of $768 \mathrm{mAh} \mathrm{g}^{-1}$ at $1 \mathrm{C}$ after the first ten cycles of activation, and maintains a specific capacity of $501 \mathrm{mAh} \mathrm{g}^{-1}$ with a low capacity fading of $0.1 \%$ per cycle after 300 cycles. In addition, multi-rate performances were also shown in Figure 3C. Specifically, when the current rate increases from 0.1 to $0.2,0.5,1,2$, and $5 \mathrm{C}$, the discharge specific capacities of the cell with a TiC-nanoparticles-coated-separator can be higher and 
more stable at around 1,412, 1,118, 914, 756, 652, and $399 \mathrm{mAh} \mathrm{g}^{-1}$, respectively. Even at a high current density of $5 \mathrm{C}$, the discharge capacity can also still maintain at about $400 \mathrm{mAh} \mathrm{g}^{-1}$. As the current density returned to $0.2 \mathrm{C}$, the reversible capacity can return to $1,035 \mathrm{mAh} \mathrm{g}^{-1}$, suggesting a good reversibility. Moreover, the EIS electrochemical performance of the battery based on cells with a TiCnanoparticles-coated-separator and common celgard separator before cycle was investigated and the result is shown in Figure 3D. In general, the low frequency slope and high frequency semicircle can be attributed to Warburg impedance (slope) and charge transfer resistance (semicircle), respectively (Zhang et al., 2020). Therefore, as shown in Figure 3D, it is obvious that the Warburg coefficient (slope) is very close in the low frequency region. However, the cell assembled with a TiCnanoparticles-coated-separator illustrates a more stable and lower charge transfer resistance $(46.2 \Omega)$ than the celgard separator $(70.6 \Omega)$ due to the good conductivity and stable structure of a TiC-nanoparticles-coated-separator.

Benefiting from the unique characteristics of $\mathrm{TiC}$ nanoparticles, the modified separator greatly improved lithium storage performances for $\mathrm{Li}-\mathrm{S}$ batteries. On one hand, nano-sized TiC can effectively contact aqueous-like LiPS and facilitate good interface interaction with them. On the other hand, TiC materials as interlayers can capture the shuttled LiPS and catalyze them tightly, contacting with cathode. Thus, the enhanced electrochemical reactivity and electronic conductivity of $\mathrm{TiC}$ nanoparticles result in less capacity fading during rate performance and a longer working time.

\section{CONCLUSION}

TiC nanoparticles have been successfully synthesized using a lower temperature of $500^{\circ} \mathrm{C}$, cheaper starting materials, and waste PTFE. This method is a more environmentally friendly way to recycle waste PTFE and requires less energy compared with the traditional carbothermal reduction of $\mathrm{TiO}_{2}$ at $1,800^{\circ} \mathrm{C}$. As a taming material for LiPS in $\mathrm{Li}-\mathrm{S}$ batteries, cells with a TiC-

\section{REFERENCES}

Berger, L. M., Gruner, W., Langholf, E., and Stolle, S. (1999). On the mechanism of carbothermal reduction processes of $\mathrm{TiO}_{2}$ and $\mathrm{ZrO}_{2}$. Int. J. Refract. Metals Hard Mater. 17, 235-243. doi:10.1016/S0263-4368(98)00077-8

Cai, K., Zhao, Y., Lang, X., Li, L., and Zhang, Q. (2020). Influence of $\mathrm{TiO}_{2} / \mathrm{TiC}$ composite materials with different crystal structures on the electrochemical properties as sulfur-loaded matrix for lithium-sulfur batteries. Int. J. Energy Res. 44, 5026-5034. doi:10.1002/er.5259

Cui, Z., Mei, T., Yao, J., Hou, B., Zhu, X., Liu, X., et al. (2018). Cabbage-like nitrogendoped graphene/sulfur composite for lithium-sulfur batteries with enhanced rate performance. J. Alloys Compd. 753, 622-629. doi:10.1016/j.jallcom.2018.04.234

Cui, Z. Q., Yao, J., Mei, T., Zhou, S. Y., Hou, B. F., Li, J., et al. (2019). Strong lithium polysulfides chemical trapping of $\mathrm{TiC}^{-} \mathrm{TiO}_{2} / \mathrm{S}$ composite for long-cycle lithiumsulfur batteries. Electrochimica Acta 298, 43-51. doi:10.1016/j.electacta.2018.12.075

Dai, W. C., Lu, L. J., Han, Y. X., Wang, L. B., Wang, J. J., Hu, J. M., et al. (2019). Facile synthesis of $\mathrm{Mo}_{2} \mathrm{C}$ nanoparticles from waste polyvinyl chloride. ACS Omega 4, 4896-4900. doi:10.1021/acsomega.8b02856 nanoparticles-coated-separator demonstrate enhanced electrochemical properties due to their high conductivity and polar property of $\mathrm{TiC}$.

\section{DATA AVAILABILITY STATEMENT}

The original contributions presented in the study are included in the article/Supplementary Material, further inquiries can be directed to the corresponding authors.

\section{AUTHOR CONTRIBUTIONS}

SL and JL designed the experiments and performed the material synthesis, measurements, data analysis and wrote the manuscript. TM provided theoretical and experimental guidance and guided the writing of manuscript. YX, ZC, GR, GH, and JJ provided helps in the characterizations. $\mathrm{KZ}$ and $\mathrm{LW}$ provided helps in the revision of the manuscript. All authors contributed to the general discussion.

\section{FUNDING}

We are very grateful to the High-level innovation and Entrepreneurship Talent introduction plan of Jiangsu Province, College Students' Training Program of Innovation and Entrepreneurship of Jiangsu Province (Nos. 201911463044Y and 202011049011Z), National Natural Science Foundation of China (21701061, 51872129 and 21831006), Natural Science Foundation of Jiangsu Province (BK20160292), Science and Technology Foundation of Huai'an City (HAB202064), Joint Open Fund of Jiangsu Collaborative Innovation Center for Ecological Building Material and Environmental Protection Equipments and Key Laboratory for Advanced Technology in Environmental Protection of Jiangsu Province (JH201815 and JH201836), and Changzhou Sci\&Tech Program (Grant No. CJ20200041) for their financial support.

Das, K., Bandyopadhyay, T. K., and Das, S. (2002). A review on the various synthesis routes of $\mathrm{TiC}$ reinforced ferrous based composites. J. Mater. Sci. 37, 3881-3892. doi:10.1023/A:1019699205003

Fei, R., Wang, H., Wang, Q., Qiu, R., Tang, S., Wang, R., et al. (2020). In situ hard-template synthesis of hollow bowl-like carbon: a potential versatile platform for sodium and zinc ion capacitors. Adv. Energy Mater. 10, 2002741. doi:10.1002/aenm.202002741

Geng, X., Yi, R., Lin, X., Liu, C., Sun, Y., Zhao, Y., et al. (2021). A high conductive $\mathrm{TiC}-\mathrm{TiO}_{2} / \mathrm{SWCNT} / \mathrm{S}$ composite with effective polysulfides adsorption for high performance Li-S batteries. J. Alloys Compd. 851, 156793. doi:10.1016/j.jallcom. 2020.156793

Lee, D. W., Alexandrovskii, S., and Kim, B. K. (2004). Mg-thermal reduction of $\mathrm{TiCl}_{4}+\mathrm{C}_{\mathrm{x}} \mathrm{Cl}_{4}$ solution for producing ultrafine titanium carbide. Mater. Chem. Phys. 88, 23-26. doi:10.1016/j.matchemphys.2004.02.005

Liu, S., Xia, X., Zhong, Y., Deng, S., Yao, Z., Zhang, L., et al. (2018). 3D TiC/C core/ shell nanowire skeleton for dendrite-free and long-life lithium metal anode. Adv. Energy Mater. 8, 1702322. doi:10.1002/aenm.201702322

Liu, Z. W., Wang, X. M., and Han, Q. Y. (2014). Synthesis of submicrometer-sized TiC particles in aluminum melt at low melting temperature. J. Mater. Res. 29, 896-901. doi:10.1557/jmr.2014.56 
Lyakhov, N., Grigoreva, T., Sepelak, V., Tolochko, B., Ancharov, A., Vosmerikov, S., et al. (2018). Rapid mechanochemical synthesis of titanium and hafnium carbides. J. Mater. Sci. 53, 13584-13591. doi:10.1007/s10853-018-2450-x

Qi, S. R., Huang, X. T., Gan, Z. W., Ding, X. X., and Cheng, Y. (2000). Synthesis of titanium carbide nanowires. J. Cryst. Growth 219, 485-488. doi:10.1016/S00220248(00)00634-5

Rasaki, S. A., Zhang, B. X., Anbalgam, K., Thomas, T., and Yang, M. H. (2018). Synthesis and application of nano-structured metal nitrides and carbides: a review. Prog. Solid State. Chem. 50, 1-15. doi:10.1016/j.progsolidstchem.2018. 05.001

Razavi, M., Rahimipour, M. R, and Rajabi-Zamani, A. H. (2007). Synthesis of nanocrystalline $\mathrm{TiC}$ powder from impure $\mathrm{Ti}$ chips via mechanical alloying. J. Alloys Compd. 436, 142-145. doi:10.1016/j.jallcom.2006.07.018

Saba, F., Sajjadi, S. A., Haddad-Sabzevar, M., and Zhang, F. M. (2018). TiCmodified carbon nanotubes, $\mathrm{TiC}$ nanotubes and $\mathrm{TiC}$ nanorods: synthesis and characterization. Ceram. Int. 44, 7949-7954. doi:10.1016/j.ceramint.2018. 01.233

Sivasankaran, S., and Kumar, K. M. J. (2015). A novel sonochemical synthesis of nano-size silicon nitride and titanium carbide. Ceram. Int. 41, 11301-11305. doi:10.1016/j.ceramint.2015.05.087

Song, M. S., Huang, B., Zhang, M. X., and Li, J. G. (2009). Study of formation behavior of $\mathrm{TiC}$ ceramic obtained by self-propagating high-temperature synthesis from Al-Ti-C elemental powders. Int. J. Refract. Metals Hard Mater. 27, 584-589. doi:10.1016/j.ijrmhm.2008.09.009

Wang, H., Zhang, Y., Ang, H., Zhang, Y., Tan, H. T., Zhang, Y., et al. (2016). A high-energy lithium-ion capacitor by integration of a $3 \mathrm{~d}$ interconnected titanium carbide nanoparticle chain anode with a pyridine-derived porous nitrogen-doped carbon cathode. Adv. Funct. Mater. 26, 3082-3093. doi:10. 1002/adfm.201505240

Wang, L. B., Cheng, Q. L., Qin, H. F., Li, Z. C., Lou, Z. S., Lu, J. J., et al. (2017). Synthesis of silicon carbide nanocrystals from waste polytetrafluoroethylene. Dalton Trans. 46, 2756-2759. doi:10.1039/c6dt04865j

Wang, L. B., Dai, W. C., Cheng, Q. L., Zhang, K. L., Yang, T. H., Mei, T., et al. (2019a). Converting waste polyethylene into $\mathrm{ZnCCo}_{3}$ and $\mathrm{ZnCNi}_{3}$ by a one-step thermal reduction process. ACS Omega 4, 15729-15733. doi:10.1021/acsomega. 9 b02406

Wang, L. B., Dai, W. C., Zhang, K. L., Mei, T., Zhuang, H. Y., Song, S. S., et al. (2018). One step conversion of waste polyethylene to $\mathrm{Cr}_{3} \mathrm{C}_{2}$ nanorods and $\mathrm{Cr}_{2} \mathrm{AlC}$ particles under mild conditions. Inorg. Chem. Front. 5, 2893-2897. doi:10.1039/c8qi00856f

Wang, L. B., Dai, W. C., Zhao, D. J., Zhang, F., Zhang, K. L., Cheng, Q. L., et al. (2019b). A simple route for the direct conversion of waste plastic to hafnium carbide nanoparticles at low temperature. Nanosci. Nanotechnol. Lett. 11, 1027-1031. doi:10.1166/nnl.2019.2979

Wang, L. B., Li, Q. W., Mei, T., Shi, L., Zhu, Y. C., and Qian, Y. T. (2012a). A thermal reduction route to nanocrystalline transition metal carbides from waste polytetrafluoroethylene and metal oxides. Mater. Chem. Phys. 137, 1-4. doi:10. 1016/j.matchemphys.2012.08.008

Wang, L. B., Li, Q. W., Zhu, Y. C., and Qian, Y. T. (2012b). A simple route for the direct conversion of waste plastic to hafnium carbide nanoparticles at low temperature. Int. J. Refract. Metals Hard Mater. 31, 288-292. doi:10.1016/j. ijrmhm.2011.10.009
Wang, L. B., Zhang, F., Dai, W. C., Cheng, Q. L., Lu, L. J., Zhang, K. L., et al. (2019c). One step transformation of waste polyvinyl chloride to tantalum carbide@ carbon nanocomposite at low temperature. J. Am. Ceram. Soc. 102, 6455-6462. doi:10.1111/jace.16650

Wang, L. B., Zhang, F., Dai, W. C., Cheng, Q. L., Zhang, K. L., Wu, Y., et al. (2019d). The synthesis of zirconium carbide nanoparticles by lithium thermal reduction of zirconium dioxide and waste plastic. Chem. Lett. 48, 604-606. doi:10.1246/cl. 190075

Wokulski, Z., and Wolaska, K. (1983). On the growth and morphology of $\mathrm{TiC}_{\mathrm{x}}$ whiskers. J. Cryst. Growth 62, 439-446. doi:10.1016/0022-0248(83)90323-8

Xiao, Y., Hwang, J. Y., and Sun, Y. K. (2016). Transition metal carbide-based materials: synthesis and applications in electrochemical energy storage. J. Mater. Chem. A 4, 10379-10393. doi:10.1039/c6ta03832h

Xu, Q., Zhang, K., Qian, J., Guo, Y., Song, X., Pan, H., et al. (2019). Boosting lithium-sulfur battery performance by integrating a redox-active covalent organic framework in the separator. ACS Appl. Energy Mater. 2, 5793-5798. doi:10.1021/acsaem.9b00920

Yu, L., Ji, W. J., Zhang, S. W., Song, Y., Liu, H., Wang, Z. F., et al. (2020). Design and preparation of continuous titanium carbide fibers via simple precursor route. Ceram. Int. 46, 25485-25492. doi:10.1016/j.ceramint.2020.07.019

Zhang, J., Huang, M., Xi, B., Mi, K., Yuan, A., and Xiong, S. (2018). Systematic study of effect on enhancing specific capacity and electrochemical behaviors of lithium-sulfur batteries. Adv. Energy Mater. 8, 20170133. doi:10.1002/aenm. 201701330

Zhang, K., Wang, L., Cai, W., Chen, L. -F., Wang, D., Chen, Y., et al. (2019). Pyridinic and pyrrolic nitrogen-enriched carbon as a polysulfide blocker for high-performance lithium-sulfur batteries. Inorg. Chem. Front. 6, 955-960. doi:10.1039/c9qi00052f

Zhang, K., Xu, Y., Lu, Y., Zhu, Y., Qian, Y., Wang, D., et al. (2016). A graphene oxide-wrapped bipyramidal sulfur@polyaniline core-shell structure as a cathode for $\mathrm{Li}-\mathrm{S}$ batteries with enhanced electrochemical performance. J. Mater. Chem. A 4, 6404-6410. doi:10.1039/c6ta01118g

Zhang, K. L., Zhang, F., Pan, H. L., Yu, J., Wang, L., Wang, D., et al. (2020). Dual taming of polysufides by phosphorus-doped carbon for improving electrochemical performances of lithium-sulfur battery. Electrochim Acta 354, 136648. doi:10.1016/j.electacta.2020.136648

Zhang, Y., Zhang, P., Li, B., Zhang, S., Liu, K., Hou, R., et al. (2020). Vertically aligned graphene nanosheets on multi-yolk/shell structured TiC@C nanofibers for stable Li-S batteries. Energy Storage Mater. 27, 159-168. doi:10.1016/j.ensm. 2020.01.029

Conflict of Interest: The authors declare that the research was conducted in the absence of any commercial or financial relationships that could be construed as a potential conflict of interest.

Copyright (C) 2021 Liu, Luo, Xiong, Chen, Zhang, Rui, Wang, Hu, Jiang and Mei. This is an open-access article distributed under the terms of the Creative Commons Attribution License (CC BY). The use, distribution or reproduction in other forums is permitted, provided the original author(s) and the copyright owner(s) are credited and that the original publication in this journal is cited, in accordance with accepted academic practice. No use, distribution or reproduction is permitted which does not comply with these terms. 